Retraction

\title{
Retraction: Chen, J. et al. Computational Fluid Dynamics Modeling of the Catalytic Partial Oxidation of Methane in Microchannel Reactors for Synthesis Gas Production. Processes 2018, 6, 83
}

\author{
Processes Editorial Office \\ MDPI, St. Alban-Anlage 66, 4052 Basel, Switzerland; processes@mdpi.com
}

Received: 28 June 2019; Accepted: 1 July 2019; Published: 10 July 2019

We have become aware that figures, tables, experimental data, and a whole paragraph in the results and discussion section of the published article [1] are identical to a previously published paper by the same authors [2]. While the authors claimed that the work was sufficiently different to the previously published work, our editorial board disagreed, and we have therefore decided to retract the paper. Despite low levels of textual overlap, the work is essentially the same as that previously reported.

MDPI is a member of the Committee on Publication Ethics and takes the responsibility to enforce strict ethical policies and standards very seriously. To ensure the addition of only high quality scientific works to the field of scholarly publication, [1] is retracted and shall be marked accordingly. We apologize to the readership of Processes for any inconvenience caused. We note that two other papers by the same author are being retracted for similar reasons $[3,4]$.

\section{References}

1. Chen, J.; Song, W.; Xu, D. Computational Fluid Dynamics Modeling of the Catalytic Partial Oxidation of Methane in Microchannel Reactors for Synthesis Gas Production. Processes 2018, 6, 83. [CrossRef]

2. Chen, J.; Song, W.; Xu, D. Catalytic partial oxidation of methane for the production of syngas using microreaction technology: A computational fluid dynamics study. Int. J. Hydrogen Energy 2018, 43, 14059-14077. [CrossRef]

3. Catalysts Editorial Office. Retraction: Chen, J. et al. Catalytic Combustion Characteristics of Methane-Air Mixtures in Small-Scale Systems at Elevated Temperatures. Catalysts 2018, 8, 439. Catalysts 2019, 9, 595. [CrossRef]

4. Energies Editorial Office. Retraction: Chen, J. et al. Production of Hydrogen by Methane Steam Reforming Coupled with Catalytic Combustion in IntegratedMicrochannel Reactors. Energies 2018, 11, 2045. Energies 2019, 12, 2642. [CrossRef]

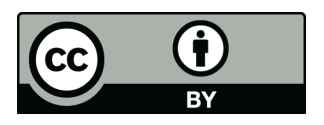

(C) 2019 by the author. Licensee MDPI, Basel, Switzerland. This article is an open access article distributed under the terms and conditions of the Creative Commons Attribution (CC BY) license (http://creativecommons.org/licenses/by/4.0/). 